BLS 34, No 1 2008. DOI: http://dx.doi.org/10.3765/bls.v34i1.3591

(published by the Berkeley Linguistics Society and the Linguistic Society of America)

\title{
Specification under Discussion ${ }^{1}$
}

\author{
LINE MIKKELSEN \\ University of California, Berkeley
}

\section{Introduction}

In her influential 1996 paper, Craige Roberts draws a distinction between information structure of sentences (ISS) and information structure of contexts (ISC). ISS partitions sentences and labels their parts with information structural notions like GROUND and FOCUS, as in (1).

$[\text { Hilary ate }]_{\text {GROUND }}[\text { bagels }]_{\text {Focus. }}$

ISC structures the inquiry pursued in a given discourse, as exemplified in (2) below for a domain of inquiry containing two individuals, Hilary and Robin, and two foods, bagels and tofu (Roberts 1996:101).

IS1. Who ate what?

a. What did Hilary eat?

$\mathbf{a}_{i}$. Did Hilary eat bagels?

Yes.

$\mathbf{a}_{i i}$. Did Hilary eat tofu?

Yes.

b. What did Robin eat?

$\mathbf{b}_{i}$. Did Robin eat bagels?

No.

$\mathbf{b}_{i i}$. Did Robin eat tofu?

Yes.

In (2), the main Question under Discussion (QUD) is Who ate what?, which has the two subquestions IS1a and IS1b. Each of these in turn has two (polar)

\footnotetext{
${ }^{1}$ The idea of examining specificational clauses in the Question under Discussion framework was suggested to me by Judith Aissen. The audiences at BLS 34 and the Berkeley Syntax and Semantics Circle provided much useful feedback, though space limitations prevent me from incorporating most of that here. Finally I thank Nick Fleisher, Russell Lee-Goldman and Maziar Toosarvandani for helpful comments on a pre-final draft.
} 


\section{Line Mikkelsen}

subquestions. Roberts argues that ISC is crucial to understanding the distribution and contribution of information structure markers in sentences. Specifically, Roberts proposes that prosodic focus in English expresses a presupposition about the structure of the current discourse. So, (1), with prosodic focus on bagels, presupposes the QUD in IS1a.

In this paper I apply the QUD framework, as developed by Roberts (1996) and Büring (2003), to a well-known puzzle in the literature on copular clauses. Early on it was noticed that specificational copular clauses exhibit a fixed topicfocus structure: NP $\mathrm{NOPIC}_{\text {TO }}$ be $\mathrm{NP}_{\mathrm{FOCUS}}$ (Halliday 1967, Akmajian 1979, Higgins 1979, Heycock and Kroch 1999, 2002, Partee 2002), whereas other types of copular clauses are not restricted in this way. The puzzle is why this should be the case. I argue that QUD cannot explain why specificational clauses have this fixed topic-focus structure, but it can draw a principled connection between two kinds of data used in the literature to demonstrate the topic-focus structure of specificational clauses, namely restrictions on specificational answers to constituent questions (section 2.1) and restrictions on specificational answers to polar questions (section 2.2). This leads me to conclude that there is information structure at the sentence level in the sense of restrictions on information structure that cannot be explained by the larger context of utterance.

\section{Question-Answer Congruence}

Long before Roberts' paper, focus and questions were tied together in Halliday's (1967) notion of question-answer congruence. A question-answer pair is congruent if the constituent in the answer that corresponds to the wh-phrase in the question is focus. In (3), A1 is congruent because the focussed constituent, Sally, corresponds to the wh-phrase of the question. (Caps indicate prosodic fous, i.e. Jackendoff's (1972) Accent A or Pierrehumbert's (1980) H*.) A2 is incongruent because the focussed constituent, chair, does not correspond to who.

(3) Q: Who took the chair?

A1: SAlly took the chair.

A2: \#Sally took the CHAIR.

More formally, Roberts defines congruence as in (4):

Congruence (Roberts 1996:111)

Move $\beta$ is congruent to a question ? $\alpha$ iff its focal alternatives $\|\beta\|$ are the Q-alternatives determined by ? $\alpha$, i.e. iff $\|\beta\|=\mathrm{Q}-\operatorname{alt}(\alpha)$.

Focus-alternatives and Q-alternatives are in turn defined as below:

(5) Focus alternative set (Roberts 1996:112)

The focus alternative set corresponding to a constituent $\beta,\|\beta\|$, is the set of all interpretations obtained by replacing all the F-marked (focused) and $w h$-constituents in $\beta$ with variables, and then interpreting the result relative 


\section{Specification under Discussion}

to each member of the set of all assignment functions which vary at most in the values they assign to those variables.

(6) Q-alternatives set (Roberts 1996:96-7; see formal definition in (1), p. 96) To derive Q-alt $(\alpha)$ "abstract over any $w h$-elements in $\alpha$ and permit the variables of abstraction to vary freely over entities of the appropriate sort in the model."

Returning to the example in (3) with these definitions in hand, we can say that A1 is congruent because $\|\mathrm{A} 1\|=\mathrm{Q}$-alt(Who took the chair?) $=$ \{Harvey took the chair, Sally took the chair, Robert took the chair, ...\}. A2 is incongruent because $\|$ A2 $\|=\{$ Sally took the chair, Sally took the book, Sally took the chalk, ... $\} \neq$ Qalt(Who took the chair?).

In addition to being more explicit, the QUD framework improves on Halliday's congruence condition in three ways that are relevant for what follows. First, it generalizes to "answers" without explicit questions. This is achieved by the condition stated in (7):

Presupposition of prosodic focus in an utterance $* \beta$ (Roberts 1996:112)

$\beta$ is congruent to the question under discussion at the time of utterance.

Applying this condition to A1 and A2 in (3), yields different results. A1 presupposes the QUD 'Who took the chair?', whereas A2 presupposes the QUD 'What did Sally take?'. This lets us understand the felicity of A1 in the context of the explicit question in (3), which matches the QUD presupposed by A1, as well as the infelicity of A2 in the context of the same explicit question, which does not match the QUD presupposed by A2. Importantly, it also makes predictions about the felicity of A1 and A2 outside question-answer pairs. The second advantage of the QUD framework, is that it generalizes to non-declaratives; the * in (7) ranges over declaratives and interrogatives. Hence a polar question like Did SAlly take the chair? presupposes the QUD 'Who took the chair?', whereas Did Sally take the CHAIR? presupposes the QUD 'What did Sally take?'. Finally, a clean distinction is drawn between coherence, which is a matter of content, and congruence, which is a matter of form (Büring 2003:517ff). Both are relevant for felicity, as can be shown by elaborating (3) as in (8):

Q: Who took the chair?

A1: SAlly took the chair.

A2: \#Sally took the CHAIR.

A3: \#SAlly eats peanuts.

$\mathrm{A} 2$ is incongruent, $\mathrm{A} 3$ is incoherent (under any pronunciation), and A1 is congruent and coherent. 


\section{Line Mikkelsen}

\section{Copular Questions and Answers}

The distinction between specificational and predicational copular clauses is part of the larger taxonomy of copular clauses proposed in Higgins (1979). While other parts of the taxonomy have been disputed, the distinction between predication and specification is generally accepted, and supported by a dossier of tests (see Higgins 1979: chapter 5). In this paper, all predicational clauses will have the form [name be description], as in (9), and all specificational clauses the form [description be name], as in (10):

(9) Sharon is the chair.

[predicational]

(10) The chair is Sharon.

[specificational]

Note that (9) and (10) are truth-conditionally equivalent, which means that they have the same content and hence the same coherence conditions. On the other hand, (9) and (10) differ in form, which opens up the possibility that they have different congruence conditions. Evidence that they do is provided in the following two subsections.

\subsection{Constituent Questions}

We start by considering the copular question in (11), and the associated ISC in (12).

Q: Who is the graduate advisor?

A1: EVE is the graduate advisor.

A2: The graduate advisor is EVE.

$[=\mathrm{IS} 2 \mathrm{~b}]$

[predicational]

[specificational]

(12) IS2. Who is who (in the department)?

a. Who is the chair?

$\mathbf{a}_{i}$. Is Sharon the chair?

Yes.

$\mathbf{a}_{i i}$. Is Eve the chair?

No.

b. Who is the graduate advisor?

$\mathbf{b}_{i}$. Is Sharon the graduate advisor?

No.

$\mathbf{b}_{i i}$. Is Eve the graduate advisor?

Yes.

In (11), A1 is predicational, A2 is specificational, and both are felicitous. This is explicable by Halliday's congruence condition: in both A1 and A2, the focus constituent is Eve and in both it corresponds to the wh-phrase of the question. It is also explicable by Roberts' congruence condition in (7): A1 and A2 both presuppose the QUD in IS2b, which is 'Who is the graduate advisor?', and that QUD is explicitly evoked by the question in (11). 


\section{Specification under Discussion}

Next consider the exchange in (13) and the associated ISC in (14).

Q: Who/What is Eve?

A3: Eve is the GRAduate advisor.

A4: \#The GRAduate advisor is Eve.

$[=\mathrm{IS} 3 \mathrm{~b}]$

[predicational]

[specificational]

(14) IS3. Who is who (in the department)?

a. Who is Sharon?

$\mathbf{a}_{i}$. Is Sharon the chair?

Yes.

$\mathbf{a}_{i i}$. Is Sharon the graduate advisor?

No.

b. Who is Eve?

$\mathbf{b}_{i}$. Is Eve the chair?

No.

$\mathbf{b}_{i i}$. Is Eve the graduate advisor?

Yes.

Again, one answer (A3) is predicational and the other (A4) is specificational, but here there is an asymmetry between them in that only the predicational answer is felicitous. The question is whether this asymmetry can be accounted for in terms of congruence. My claim is that it cannot. Starting with Halliday's notion, we observe that A3 and A4 are both congruent to the question in (13), since in both the focused constituent is the graduate advisor and in both that corresponds to the wh-phrase of the question. Similarly, A3 and A4 both presuppose the QUD in IS3b, namely 'Who is Eve?', which is matched by the explicit question in (13). Hence Roberts' congruence condition in (7) is satisfied by both A3 and A4 and both are predicted to be felicitous in the cited context, contrary to fact.

It is instructive to compare A4 in (12) to A2 in (3), repeated here as (15):

\section{Q: Who took the chair?}

A2: \#Sally took the CHAIR.

Both are infelicitous, but their status within the QUD framework is different. A2 is incongruent (by (7) it presupposes a QUD that is not matched by the explicit question), whereas A4 is congruent (it presupposes a QUD that is matched by the explicit question) and coherent (its propositional content matches that of the question).

Büring (2003:530) notes that some strategies for answering a question may be dispreferred, not on linguistic grounds, but because our world knowledge deems them inefficient or pointless. His example is a strategy of going by clothing, as opposed to people, when trying to determine which pop stars wore which clothing during a concert. I don't think we can appeal to world knowledge in ruling out A4. After all, it presupposes the exact same QUD as A3, which is perfect- 


\section{Line Mikkelsen}

ly felicitous. The problem with A4 thus does seem to be a linguistic one. We could propose that specificational clauses of the form [NP1 be NP2] cannot "answer" QUDs of the form [Who is NP2?], as a way to account for the infelicity of A4. I see two problems with this. First, "answer" in the required sense is not part of Roberts' system (nor of Büring's). Second, it obscures the fact that the problem with A4 is a sentence-internal one (note that A4 is infelicitous in any context): a specificational clause does not allow focus (or focus prosody) on the subject. This latter formulation, which is common in the literature on copular clauses, seems no more stipulative than the hypothetical QUD-answerability condition, and, unlike the QUD-answerability condition, it explicitly identifies the trouble spot. More importantly, though, neither brings us any closer to understanding the original puzzle; why do specificational clauses have the fixed information structure they do? On the other hand, the QUD framework does provide a systematic link between the data in (11) and (13), which is frequently cited in the literature on copular clauses, and another set of data, which is cited less frequently, but no less instructive. I turn to this data next.

\subsection{Polar Questions}

In (16) we have a polar copular question and two felicitous copular answers; one predicational (A1) and one specificational (A2):

(16) Q: Is Eve the chair?

A1: No, SHAron is the chair.

A2: No, the chair is SHAron.

The first thing to note is that Halliday's notion of question-answer congruence does not apply to (16): there is no wh-phrase in the question and hence no predictions about where the focus must fall in the answers. Roberts' congruence condition from (7) does apply, since it works directly off the focus prosody in the answer to restrict the QUD. This process is sketched for A1 in (17) below:

i. A1 contains focus prosody (SHAron) and hence carries the presupposition that it is congruent to the QUD at the time of utterance. ii. To be congruent, the focus-alternatives of A1 must equal the questionalternatives of the QUD, that is $\|\mathrm{A} 1\|=\mathrm{Q}$-alt(QUD).

iii. $\|\mathrm{A} 1\|=\{$ Eve is the chair, Sharon is the chair, Gary is the chair, ... $\}$ iv. $\{$ Eve is the chair, Sharon is the chair, Gary is the chair, ... $\}=$ Qalt(Who is the chair?)

The calculation in (17) shows that A1 is congruent to the QUD 'Who is the chair?'. The reason A1 is felicitous in (16) is that the stated question Is Eve the chair? is a subquestion of the presupposed QUD, as can be seen in IS2 (the presupposed QUD is IS2a and the explicit question corresponds to IS2 $\mathrm{a}_{\mathrm{ii}}$ ). A2 is felicitous in (15) for the exact same reason: since A2 has focus on the same constit- 


\section{Specification under Discussion}

uent as A1, they have the same focus-alternatives and, hence, presuppose the same QUD. are different:

Consider (18) next. The question is the same as in (16), but the answers

\section{Q: Is Eve the chair?}

A3: No, Eve is the GRAduate advisor.

A4: \#No, the GRAduate advisor is Eve.

The predicational answer in A3 is felicitous, but the specificational answer in A4 is not. We calculate the focus presupposition of A3 in (19):

i. A3 contains focus prosody (the GRAduate advisor) and hence carries the presupposition that it is congruent to the QUD at the time of utterance.

ii. To be congruent, the focus-alternatives of $\mathrm{A} 3$ must equal the questionalternatives of the QUD, that is $\|\mathrm{A} 3\|=\mathrm{Q}$-alt(QUD).

iii. $\|\mathrm{A} 3\|=$ Eve is the chair, Eve is the graduate advisor, Eve is the undergraduate advisor, ... $\}$

iv. \{Eve is the chair, Eve is the graduate advisor, Eve is the undergraduate advisor, ... $\}=$ Q-alt(Who is Eve?)

The focus on the graduate advisor in A3 presupposes that the QUD is 'Who is Eve?'. As seen in IS3, that is a super question of the explicit question posed in (18) (the presupposed QUD is IS3b and the explicit question is IS $3 b_{i}$ ), which explains the felicity of A3 in this exchange. Turning to A4, we see that it too has focus prosody on the graduate advisor, which means that it has the same focus alternatives as A3 and, therefore, that it too presupposes IS3b. Since A3 is congruent, A4 is too. A4 also carries the same propositional content as A3, so if A3 is coherent, A4 is too. So why is A4 infelicitous? Well, A4 in (18) is identical to A4 in (13) and following the discussion of the latter in section 2.1 we could say that both are bad because they are specificational clauses that presuppose a QUD of the form 'Who is NAME?' (appealing to ISC) or we could say that both are bad because they are specificational clauses with focus on the subject (appealing to ISS). As argued in section 2.1, these seem equally stipulative. Again, an extralinguistic explanation for the infelicity of A4 in (18) is effectively ruled out by the observation that A4 invokes the exact same QUD and strategy as the perfectly felicitous A3.

\subsection{Taking Stock}

The examination of specificational clauses above reveals that the QUD framework cannot explain why they invariably have the form $\mathrm{NP}_{\text {TOPIC }}$ be $\mathrm{NP}_{\mathrm{FOCUS}}$, but it does connect the two sets of data - specification answers to constituent questions and specificational answers to polar questions - in a systematic way. Earlier work (e.g. Wunderlich 1980, Kiefer 1980, and Yadugiri 1986) has pointed out 


\section{Line Mikkelsen}

that polar questions regularly invoke constituent questions, but Roberts (1996) and Büring (2003) provide a formal and fully general framework that can incorporate these observations, though no formal incorporation has been provided here.

If the focus properties of specificational clauses cannot be explained by considering the information structure of contexts, it must be a sentence-internal matter. As pointed out to me by Maziar Toosarvandani, this groups specificational clauses with focus constructions like $i t$-clefts and possibly clauses containing focus "associators" like only and even. One difference between these and specificational clauses is that in the former, there is some discernable linguistic material to hang the focus structure on, so to speak, namely the cleft structure and the word only/even. In specificational clauses there is only word order. In so far as word order is a matter of syntax, this raises the question of whether syntax "knows" that this word order is associated with a particular topic-focus structure. This question is answered in the positive in Mikkelsen (2005: chapter 9), where I propose that a topic feature is active in the syntax and centrally involved in the derivation of specificational clauses. One could also posit a specificational construction, in the sense of Kay and Fillmore (1999), and tie both word order and topic-focus structure to the construction. Finally, one could reject any direct link between syntax (word order) and information structure (topic and focus) by analyzing the infelicity of specificational clauses like A4 in (13) and in (18) as a syntax-phonology mismatch: specificational clauses may not carry focus prosody on their subject. The data discussed in this paper does not help us decide between these options, but it does demonstrate that some restriction must be imposed at the clause level. It is not enough to appeal to context.

\section{A Final Speculation}

So why is A4, and more generally, specificational clauses with focus (prosody) on the subject infelicitous? I don't know, but the following possible explanation was suggested to me by Daniel Büring (public comment, February 10, 2008): the unmarked position for focus in English is the VP and the unmarked "position" for the semantic predicate is likewise the VP. Given this specificational clauses with subject focus are doubly marked: the focus falls on the subject (not on the VP) and the semantic predicate is realized in subject position (not as the VP; this is the major claim of the analysis of specificational clauses in Mikkelsen 2005). The grammar of English is flexible enough to allow either of these: there are indisputable cases of subject focus, and, if the analysis of specificational clauses in Mikkelsen (2005) is right, a semantically predicative NP may surface in subject position under particular circumstances. But perhaps it is not flexible enough to allow both of these to occur together, as is the case in a specificational clause with subject focus. If something like this is on the right track, we need to ask whether this restriction is conventional or actively computed in an OT-style grammar. Again, I don't know, but the data in (20) (partly due to Bill Ladusaw) could be taken to suggest the latter: 


\section{Specification under Discussion}

(20) Q: Is that Eve?

A1: No, that's SHAron.

A2: No, THAT's Eve.

A3: *No, Eve's THAT.

Q, A1, and A2 are identificational clauses in Higgins' taxonomy. They characteristically involve a demonstrative subject and an individual-denoting post-copular element, and have been argued to be specificational clauses with pronominal subjects (see Mikkelsen 2007 and references cited there). If they are indeed specificational clauses, it is no surprise that A1 is felicitous: the focus falls on the post-copular element and presupposes a QUD compatible with the explicit question. It is more surprising that A2 is felicitous, since it involves subject focus. A3 shows that a "predicational" version of A2 is impossible. From this one could reason as follows: normally specificational clauses with subject focus lose out to their predicational variants, which have a "better" focus-syntax alignment (focus inside VP) and a "better" semantics-focus alignment (predicative element inside VP), but when the predicational variant is unavailable (as is the case for a specificational clause with a demonstrative subject), a specificational clause with subject focus surfaces as the best expression of a given content.

\section{References}

Akmajian, Adrian. 1979. Aspects of the Grammar of Focus in English. New York: Garland.

Büring, Daniel. 2003. On D-Trees, Beans, and B-Accents. Linguistics and Philosophy 26(5):511-545.

Halliday, M.A.K. 1967. Notes on transitivity and theme in English (Part 2). Journal of Linguistics 3(2):199-244.

Heycock, Caroline and Anthony Kroch. 1999. Pseudocleft Connectedness: Implications for the LF Interface Level. Linguistic Inquiry 30(3):365-397.

Heycock, Caroline and Anthony Kroch. 2002. Topic, Focus, and Syntactic Representations. In Line Mikkelsen and Christopher Potts, eds., Proceedings of West Coast Conference on Formal Linguistics 21, 101-125. Somerville, MA: Cascadilla Press.

Higgins, Roger Francis. 1979. The Pseudo-cleft Construction in English. New York: Garland.

Jackendoff, Ray. 1972. Semantic Interpretation in Generative Grammar. Cambridge, MA: Massachusetts Institute of Technology Press.

Kay, Paul and Charles J. Fillmore. 1999. Grammatical Constructions and Linguistic Generalizations: The What's $X$ doing Y? Construction. Language 75(1):133. 


\section{Line Mikkelsen}

Kiefer, Ferenc. 1980. Yes-No Questions and Wh-Questions. In John R. Searle, Ferenc Kiefer, and Manfred Bierwisch, eds., Speech Act Theory and Pragmatics. 97-119. Dordrecht: D. Reidel.

Mikkelsen, Line. 2005. Copular Clauses: Specification, Predication and Equation. Amsterdam: John Benjamins.

Mikkelsen, Line. 2007. On so-called truncated clefts. In Ljudmila Geist and Björn Rothstein eds., Kopulaverben und Kopulasätze: Intersprachliche und Intrasprachliche Aspekte, 47--68. Tübingen: Niemeyer Verlag.

Partee, Barbara. 2000. Copula Inversion Puzzles in English and Russian. In Kiyomi Kusumoto and Elisabeth Villalta, eds., Issues in Semantics. (University of Massachusetts Occasional Papers 23), 183-208. Amherst, MA: University of Massachusetts.

Pierrehumbert, Janet (1980) The Phonology and Phonetics of English Intonation. $\mathrm{Ph} . \mathrm{D}$. diss. Massachusetts Institute of Technology.

Roberts, Craige. 1996. Informative Structure in Discourse: Toward an Integrated Formal Theory of Pragmatics. In Jae Hak Yoon and Andreas Kathol, eds., OSU Working Papers in Linguistics 49: Papers in Semantics, 91-136. Colombus, OH: The Ohio State University.

Wunderlich, Dieter. 1981. Questions about Questions. In Wolfgang Klein and William Levelt, eds., Crossing the Boundaries in Linguistics, 131-176. Dordrecht: D. Reidel.

Yadugiri, M. A. 1986. Some Pragmatic Implications of the Use of Yes and No in response to Yes-No Questions. Journal of Pragmatics 10(2):199-210.

\section{Line Mikkelsen}

University of California, Berkeley

Department of Linguistics

1203 Dwinelle Hall

Berkeley, CA 94720-2650

mikkelsen@berkeley.edu 